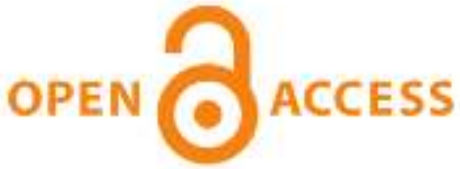

\section{International Journal of Applied Sciences and Biotechnology}

\section{A Rapid Publishing Journal}

ISSN 2091-2609

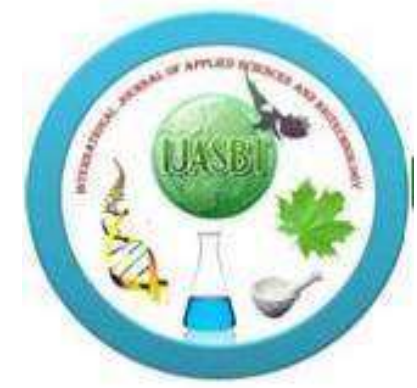

\section{Available online at:}

http://www.ijasbt.org

$\&$

http://www.nepjol.info/index.php/IJASBT/index

\section{Indexing and Abstracting}

CrossRef, Google Scholar, Global Impact Factor, Genamics, Index Copernicus, Directory of Open Access Journals, WorldCat, Electronic Journals Library (EZB), Universitätsbibliothek Leipzig, Hamburg University, UTS (University of Technology, Sydney): Library, International Society of Universal Research in Sciences (EyeSource), Journal Seeker, WZB, Socolar, BioRes, Indian Science, Jadoun Science, Jour-Informatics, Journal Directory, JournalTOCs, Academic Journals Database, Journal Quality Evaluation Report, PDOAJ, Science Central, Journal Impact Factor, NewJour, Open Science Directory, Directory of Research Journals Indexing, Open Access Library, International Impact Factor Services, SciSeek, Cabell's Directories, Scientific Indexing Services, CiteFactor, UniSA Library, InfoBase Index, Infomine, Getinfo, Open Academic Journals Index, HINARI, etc.

\section{CODEN (Chemical Abstract Services, USA): IJASKD}

Vol-2(4) December, 2014
Impact factor*: $\mathbf{1 . 4 2 2}$

Scientific Journal Impact factor\#: $\mathbf{3 . 4 1 9}$ Index Copernicus Value: $\mathbf{6 . 0 2}$

\section{SEM-Biotech}

Publishing

*Impact factor is issued by Universal Impact Factor. Kindly note that this is not the IF of Journal Citation Report (JCR). 


\title{
EXTRACTION OF JUTE GENOMIC DNA: DIFFICULTIES AND SOLUTIONS
}

\author{
A. K. M. Shahadat Hossain ${ }^{1}$, Md. Abdul Latif ${ }^{2}$, Bipul Kumar Biswas², Saidin Saclain ${ }^{2}$, Md Salahuddin ${ }^{3}$, M. Abu \\ Sayed $^{4 *}$, Md. Mahboob Hussain ${ }^{1}$, Sheik Md Moniruzzaman ${ }^{5}$ and Md. Shahidul Islam ${ }^{2}$ \\ ${ }^{1}$ Bangladesh Jute Research Institute, Bangladesh, \\ ${ }^{2}$ Department of Biotechnology, Bangladesh Agricultural University, Mymensingh-2202, Bangladesh, \\ ${ }^{3}$ Department of Physiology, Bangladesh Agricultural University, Mymensingh-2202, Bangladesh, \\ ${ }^{4}$ Department of Biochemistry and Molecular Biology, Hajee Mohammad Danesh Science and Technology University, Dinajpur-500, Bangladesh, \\ ${ }^{5}$ Department of Biochemistry and Molecular Biology, Bangladesh Agricultural University, Mymensingh-2202, Bangladesh \\ *Corresponding Author's email: sayed_bmb@yahoo.com
}

\begin{abstract}
The plant parts of jute are composed of highly viscous substances and phenolic compounds which make nuisance to extract good quality genomic DNA (gDNA). Here different methods viz., phenol chloroform isoamylalcohol extraction and ethanol precipitation method; potassium acetate method and Cetyl trimethylammonium bromide (CTAB) method were applied for isolating the jute gDNA from leaves of 14 and 40 day's plants. All of these methods were unable to extract good quality gDNA from jute leaves. That is why, in this experiment, the concentration and chemical compositions of CTAB method were modified for obtaining good quality jute gDNA. Polyvinylpyrrolidone (PVP) was added in the $\mathrm{CTAB}$ extraction buffer and $\beta$ mercaptoethanol was used while grinding the leaf tissues with CTAB extraction buffer. It was found that good quality gDNA was obtained using modified CTAB method from 14 day's plant's leaves but low quality gDNA was obtained from 40 day's plant's leaves. These were confirmed by $0.8 \%$ agarose gel electrophoresis. Considering the visual quality of the banding patterns and their reproducibly MHR24 (5'-TTCCCTCCCA-3') and MHR21 (5-'CCCGAAGCGA-3') primers were selected out of 8 Random Amplified Polymorphic DNA (RAPD) primers for PCR. A total number of 11 loci were identified by these RAPD primers. Popgen 32 software was used for analyzing the RAPD data. The number of polymorphic loci was one and the percentage was 9.09 which stated that a low level of genetic variations was existed among the jute accessions. In the dendrogram, jute accession CC875 (C. capsularis) was grouped in one cluster while CC894 (C. capsularis) and CC896 (C. capsularis) accessions were grouped in another cluster.
\end{abstract}

Key Words: Jute; DNA extraction; phenolic compounds; RAPD.

\section{Introduction}

Jute (Corchorus spp., Malvaceae) is one of the major cash crops of Bangladesh (Haque et al, 2004). Around 10\% of the total labor force of Bangladesh earns their livelihood from activities related to the production and processing of jute and allied fibers (Saha, 2006). In the Gene Bank of Bangladesh Jute Research Institute (BJRI) there are 5936 accessions of jute and allied fiber germplasms comprising 15 species of Corchorus and 22 species of Hibiscus (Haque et al., 2007). A number of methods have already been developed to extract gDNA from plant tissues such as phenol chloroform isoamylalcohol extraction and ethanol precipitation method (Rahman et al., 2006), potassium acetate method (Dellaporta et al., 1983), CTAB method (Doyle and Doyle, 1990). Isolation of gDNA is necessary for molecular characterization of plants, facilitating marker assisted breeding, and also for genomic studies. However, the traditional protocols of plant's gDNA extraction are not suitable for jute gDNA extraction because the plant materials of jute contain high level of polysaccharides, phenolics (Haque et al., 2004), mucilage (Ogunkanmi et al., 2010). These substances hamper extraction of jute nucleic acids and make the nucleic acids unstable (Haque et al., 2004). Polyphenols act as powerful oxidizing agents which can reduce the yield and purity of extracted DNA (Porebski et al., 1997). To overcome the problems associated with jute gDNA extraction of, CTAB method has been modified.

\section{Materials and Methods}

Potassium acetate method (Dellaporta et al., 1983); phenol chloroform isoamylalcohol extraction and ethanol precipitation method (Rahman et al., 2006); CTAB method (Doyle and Doyle, 1990) were used to extract jute gDNA but good quality gDNA was not obtained using these methods. Finally, CTAB method was modified for obtaining good quality gDNA. The details of the modification of CTAB method and genome extraction protocol are given below. 
Composition of CTAB extraction buffer and preparation

CTAB extraction buffer was comprised of CTAB powder (0.02 g/ml), EDTA (0.5 M, pH: 8.0), Tris $\mathrm{HCl}$ (1 M, pH 8.0), $\mathrm{NaCl}(5 \mathrm{M}), \mathrm{PVP}(0.01 \mathrm{~g} / \mathrm{ml})$ and $\mathrm{ddH}_{2} \mathrm{O}$. $\mathrm{NaCl}$, EDTA and Tris $\mathrm{HCl}$ were autoclaved before mixing all together and CTAB powder was also preheated in incubator for 5 minutes at $60^{\circ} \mathrm{C}$.

\section{Leaf collection and preparation}

Leaves were taken from 14 day's and 40 day's old jute plants. Leaves were cut into small pieces. On an average of $25 \mathrm{mg}$ leaf sample was taken. Leaf samples were submersed in $100 \%$ alcohol and then washed in $\mathrm{ddH}_{2} \mathrm{O}$ and soaked in tissue paper.

\section{Extraction and purification of $g D N A$}

$500 \mu \mathrm{l} \mathrm{CTAB}$ extraction buffer was taken in each eppendorf tube containing $25 \mathrm{mg}$ of leaf samples. Then $2 \mu \mathrm{l}$ of $\beta$ mercaptoethanol was added in each tube. After that the samples were grinded by the homogenizers. Again, $300 \mu 1$ CTAB extraction buffer was added in each tube and then mixed by short centrifugation for 1 minute. The tubes were then heated for 5 minutes in water bath at $65^{\circ} \mathrm{C}$. Tubes were then vortexed for 20 seconds followed by heating in water bath for 10 minutes at $65^{\circ} \mathrm{C}$. The tubes were then centrifuged for 5 minutes at $14000 \mathrm{rpm}$. $600 \mu \mathrm{l}$ supernatant was then taken to a new tube. Then, $600 \mu \mathrm{l}$ phenol: chloroform: isoamylalcohol $(25: 24: 1)$ was added to each tube. The solution was mixed properly by inverting the tubes and vortexed for 20 seconds and then centrifuged again for 10 minutes. $400 \mu \mathrm{l}$ supernatant was then transferred to a new tube. Then, $400 \mu \mathrm{l}$ chloroform: isoamylalcohol (24:1) was added to each tube and mixed well by inverting the tubes and vortexed for 20 seconds. The tubes were then centrifuged for 10 minutes at $14000 \mathrm{rpm}$. $400 \mu \mathrm{l}$ supernatant was taken to a new tube. Then, $50 \mu \mathrm{l}$ sodium acetate ( $\mathrm{pH}$ 5.2) was added to each tube. Sodium acetate was autoclaved before adding in each tube. Then, $900 \mu \mathrm{l}$ ice cold absolute ethanol was added to each tube. Thread like DNA was observed in each tube by simply inverting the tubes. Then the tubes were kept in a freezer at $-20^{0} \mathrm{C}$ for at least 20 minutes. The tubes were then centrifuged for 15 minutes. The DNA pellet was attached to the wall of the tubes, ethanol was discarded from the tubes. Then, $1 \mathrm{ml}$ ice cold isoamylalcohol was added to each tube. The tubes were centrifuged for 15 minutes. The DNA pellets were attached to the wall of the tubes. Then, ethanol was discarded from the tubes and air dried. Finally, $50 \mu \mathrm{l}$ Tris-EDTA (TE) buffer was added to each tube.

\section{Removal of RNA}

$50 \mu \mathrm{l}$ of DNA stock solution was dissolved in $340 \mu \mathrm{l}$ sterilized $\mathrm{ddH}_{2} \mathrm{O} .20 \mu \mathrm{l}$ RNase was added to degrade RNA. Mixture was incubated for 20 minutes at $25^{\circ} \mathrm{C}$. $420 \mu \mathrm{l}$ phenol: chloroform: isoamylalcohol $(25: 24: 1)$ was added and mixed properly. Mixture was centrifuged for 10 minutes at $14000 \mathrm{rpm}$ and then transferred the supernatant $(500 \mu 1)$ into a new eppendorf tube. Again, $420 \mu 1$ phenol: chloroform: isoamylalcohol (25:24:1) was added and vortexed for 20 seconds. Then, tubes were centrifuged for 10 minute at $14000 \mathrm{rpm}$ and transferred the supernatant (500 $\mu 1$ ) into a new eppendorf tube. Then, $40 \mu 15 \mathrm{M}$ sodium acetate was added in each tube and mixed properly. After that, $1000 \mu 1$ of $100 \%$ ice cold ethanol was added and mixed gently. Then, the mixture was centrifuged for 20 minutes at $14000 \mathrm{rpm}$ and ethanol was removed. After that, $1000 \mu \mathrm{l}$ of $70 \%$ ice cold ethanol was added and mixed gently. Then, mixture was centrifuged for 10 minutes at $14000 \mathrm{rpm}$. Again, ethanol was removed and DNA pellets were air dried for 3 to 5 hours. Finally, the pellets were suspended in $60 \mu 1$ of $1 \mathrm{X}$ TE buffer and stored at $-20^{\circ} \mathrm{C}$.

\section{Quantification of DNA (Spectrophotometric method)}

The optical density (OD) of the isolated gDNA was measured at $260 \mathrm{~nm}$ wavelength to assess the quantity of gDNA (Table 1).

\section{PCR conditions and data analysis}

Two primers were selected among eight RAPD primers for polymerase chain reaction (Table 2). The total volume of PCR cocktail was $10 \mu 1$ per sample (Table 3 ). PCR cycling was comprised of five steps (Table 4). PCR products were run in $1.4 \%$ agarose gel. Electrophoresis was conducted at 120 volt for 90 minutes. The gel was stained in ethidium bromide solution for 15 minutes. Then, the gel was placed on gel documentation system for visualization of the gDNA bands. DNA fragments that were amplified by the selected primers were scored as present ' 1 ' or absent ' 0 ' for all of the accessions that were studied and the scores obtained using the primers in the RAPD analysis were then pooled to create a single data matrix. Popgen 32 (Yeh et al., 1999) software was used to estimate polymorphic loci, Nei's (1978) gene diversity, gene flow, and to construct a UPGMA dendrogram among the jute accessions.

Table 1: Quantity assessment of gDNA, isolated from 14 and 40 day's plants.

\begin{tabular}{|c|c|c|c|c|}
\hline Genotypes & $\begin{array}{l}\text { OD } 260 \\
\text { (14 day's) }\end{array}$ & $\begin{array}{l}\text { gDNA Conc. }(\mathrm{ng} / \mu \mathrm{l}) \\
\text { (14 day's) }\end{array}$ & $\begin{array}{l}\text { OD }_{260} \\
\text { (40 day's) }\end{array}$ & $\begin{array}{l}\text { gDNA Conc. }(\mathrm{ng} / \mu \mathrm{l}) \\
(40 \text { day's) }\end{array}$ \\
\hline CC875 (C. capsularis) & \multirow{2}{*}{$\begin{array}{l}0.007 \\
0.009\end{array}$} & 350 & 0.006 & 300 \\
\hline CC894 (C. capsularis) & & 450 & 0.007 & 350 \\
\hline CC896 (C. capsularis) & 0.007 & 350 & 0.006 & 300 \\
\hline
\end{tabular}

N.B.: All the accessions were collected from Bangladesh Jute Research Institute, Dhaka 
Table 2: RAPD primers that were screened in the study

\begin{tabular}{llc}
\hline Primer's code & Base sequence & Melting temperature (Tm) \\
\hline MHR17 & CTGCATCGTG & $25^{\circ} \mathrm{C}$ \\
MHR18 & CCTAGGTCAG & $25^{\circ} \mathrm{C}$ \\
MHR19 & ACGCGCATGT & $25^{\circ} \mathrm{C}$ \\
MHR20 & GACGCCACAC & $27^{\circ} \mathrm{C}$ \\
MHR21* & CCCGAAGCGA & $27^{\circ} \mathrm{C}$ \\
MHR22 & GTGGCTTGGA & $27^{\circ} \mathrm{C}$ \\
MHR23 & GTTACGGACC & $25^{\circ} \mathrm{C}$ \\
MHR24* & TTCCCTCCCA & $25^{\circ} \mathrm{C}$ \\
\hline Selected primers for final RAPD analysis of jute accessions. & &
\end{tabular}

* Selected primers for final RAPD analysis of jute accessions.

Table 3: Components of PCR cocktail (for 40 Cycles)

\begin{tabular}{lc}
\hline Reagents & Amount per sample $(\boldsymbol{\mu l})$ \\
\hline gDNA $(50 \mathrm{ng} / \mu \mathrm{l})$ & 2 \\
Primer $(10 \mu \mathrm{M})$ & 2 \\
Taqbuffer $(10 \mathrm{X})$ & 1 \\
$\mathrm{dNTPs}$ & 1 \\
$\mathrm{MgCl}_{2}$ & 0.3 \\
$\mathrm{ddH}_{2} \mathrm{O}$ & 3.5 \\
$T a q$ DNA polymerase & 0.2 \\
\hline Total & 10 \\
\hline
\end{tabular}

Table 4: PCR cycling conditions

\begin{tabular}{lll}
\hline PCR cycling step & Temperature & $\begin{array}{l}\text { Protocol runs } \\
\text { (Minutes) }\end{array}$ \\
\hline Enzyme Activation & $94^{\circ} \mathrm{C}$ & 3 \\
Denaturation & $94^{\circ} \mathrm{C}$ & 1 \\
Annealing & $35^{\circ} \mathrm{C}$ & 1 \\
Extension & $72^{\circ} \mathrm{C}$ & 2 \\
Final extension & $72^{\circ} \mathrm{C}$ & 7 \\
\hline
\end{tabular}

\section{Results and Discussion}

The quantity of gDNA depends on the amount of leaf tissues taken. The experiment was performed on three jute accessions (CC875, CC894, and CC896) using existing methods viz. phenol chloroform isoamylalcohol extraction, potassium acetate method (Dellaporta et al., 1983), and ethanol precipitation method (Rahman et al., 2006) and CTAB method (Doyle and Doyle, 2000). High pigmentation was found on gDNA while using potassium acetate method; phenol chloroform isoamylalcohol extraction and ethanol precipitation method and CTAB method. This was because the phenolics and viscous substances were not completely removed that were mingled with the gDNA. Electrophoresis was hampered by these disturbing substances. As a result, no bands were seen in the gel documentation using these methods, gDNA was extracted from the leaves of both 14 and 40 day's plants. Finally, the concentration and chemical compositions of existing CTAB method were modified for obtaining good quality gDNA. PVP was added in the CTAB extraction buffer and $\beta$ mercaptoethanol was added during homogenizing the leaf samples with CTAB extraction buffer. These two chemicals worked very well for removing the phenolics and viscous substances from the leaves of 14 day's plants. However, PVP and $\beta$ mercaptoethanol were unable to remove these substances from the leaves of 40 day's plants. The fact was that old leaves accumulated high amount of phenolics and viscous substances than the younger ones. The gDNAs of 14 day's plants were presented in lanes 1-3 while gDNAs of 40 day's plants were in lanes 4-6 (Fig. 1). It was found that good quality gDNA bands were obtained from 14 day's plants. The highest level of gene diversity value and Shannon's Information Index (Table 5) was found in the locus mhr24-4. Overall gene frequency of three jute accessions was presented in Table 6. The lowest gene frequency (0.3333) was obtained in case of locus mhr24-4. Only one polymorphic locus was found among these three jute accessions which stated that a very low level of genetic variations existed among them. In the dendrogram (Fig. 4), jute accession CC875 grouped one cluster while CC894 and CC896 grouped another cluster.

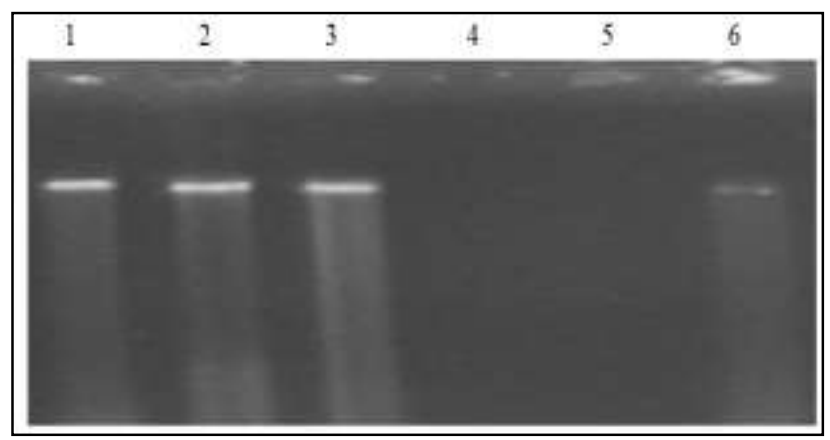

Fig. 1: DNA profile of jute.

gDNAs were run on $0.8 \%$ agarose gel. Lane 1-3: gDNA samples of 14 day's plants and Lane 4-6: gDNA samples of 40 day's plants. The optical density was ranged from 0.006 to 0.009 . 
Table 5: Summary of the genetic variation statistics for all loci

\begin{tabular}{lccccc}
\hline Locus & Sample Size & $\mathbf{n a}^{*}$ & $\mathbf{n e}^{*}$ & $\mathbf{h}^{*}$ & $\mathbf{I}^{*}$ \\
\hline mhr24-1 & 3 & 1.0000 & 1.0000 & 0.0000 & 0.0000 \\
mhr24-2 & 3 & 1.0000 & 1.0000 & 0.0000 & 0.0000 \\
mhr24-3 & 3 & 1.0000 & 1.0000 & 0.0000 & 0.0000 \\
mhr24-4 & 3 & 2.0000 & 1.8000 & 0.4444 & 0.6365 \\
mhr24-5 & 3 & 1.0000 & 1.0000 & 0.0000 & 0.0000 \\
mhr24-6 & 3 & 1.0000 & 1.0000 & 0.0000 & 0.0000 \\
mhr21-1 & 3 & 1.0000 & 1.0000 & 0.0000 & 0.0000 \\
mhr21-2 & 3 & 1.0000 & 1.0000 & 0.0000 & 0.0000 \\
mhr21-3 & 3 & 1.0000 & 1.0000 & 0.0000 & 0.0000 \\
mhr21-4 & 3 & 1.0000 & 1.0000 & 0.0000 & 0.0000 \\
mhr21-5 & 3 & 1.0000 & 1.0000 & 0.0000 & 0.0000 \\
\hline Mean & 3 & 1.8889 & 1.5658 & 0.3288 & 0.4888 \\
St. Dev. & & 0.3015 & 0.2412 & 0.1340 & 0.1919 \\
\hline
\end{tabular}

N.B: na *= Observed number of alleles, ne *= Effective number of alleles, h *= Nei's (1973) gene diversity, I *= Shannon's Information index

Table 6: Overall gene frequency

\begin{tabular}{ll}
\hline Loci & Frequency \\
\hline mhr24-1 & 1.0000 \\
mhr24-2 & 1.0000 \\
mhr24-3 & 1.0000 \\
mhr24-4 & 0.3333 \\
mhr24-5 & 1.0000 \\
mhr24-6 & 1.0000 \\
mhr21-1 & 1.0000 \\
mhr21-2 & 1.0000 \\
mhr21-3 & 1.0000 \\
mhr21-4 & 1.0000 \\
mhr21-5 & 1.0000 \\
\hline
\end{tabular}

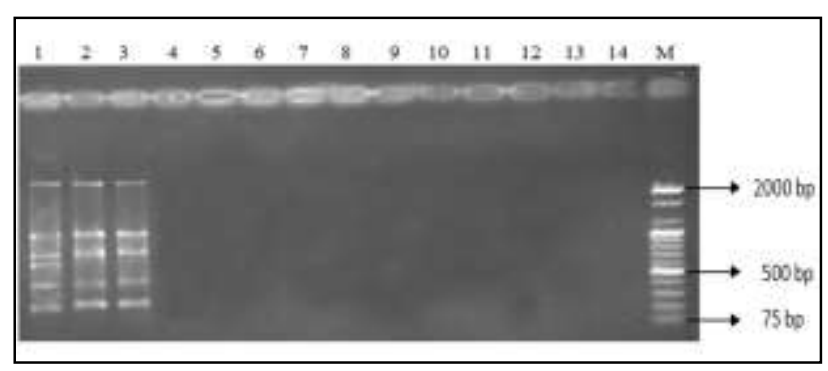

Fig. 2: Banding patterns of jute accessions using primer MHR24 (5'-TTCCCTCCCA-3').

Lane 1-3=CC875, CC894, CC896 jute accessions; Lane 4-14= negative conrols; Lane $\mathrm{M}=1 \mathrm{kbp}$ DNA ladder.

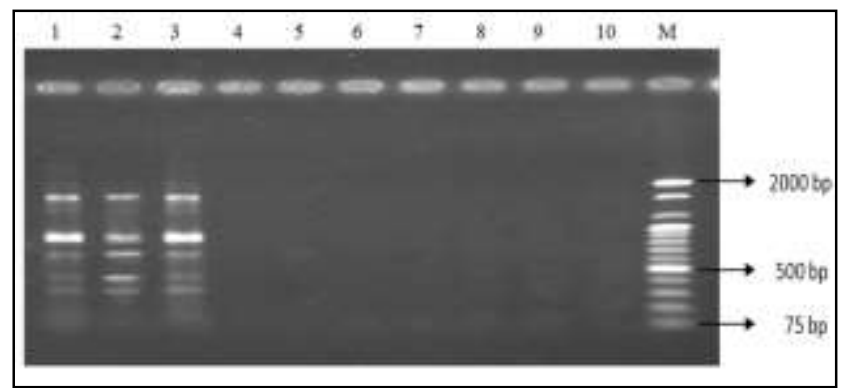

Fig. 3: Banding patterns of jute accessions using primer MHR21 (5'-CCCGAAGCGA-3').

Lane 1-3=CC875, CC894, CC896 jute accessions; Lane 4-10= negative controls; Lane $\mathrm{M}=1 \mathrm{kbp}$ DNA ladder.

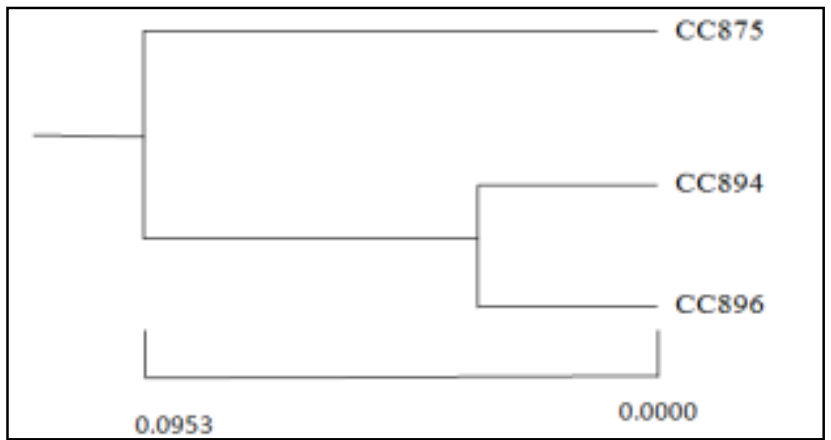

Fig. 4: UPGMA dendrogram was based on genetic distances of jute accessions.

Accession CC894 and CC896 shared more genetically similarities than accession CC875.

\section{Acknowledgements}

The authors were grateful to USDA laboratory of Biotechnology and Professor Muhammed Hussain Central Laboratory of Bangladesh Agricultural University for allowing them to conduct the research work. This was a coordinate project on characterization of important plant genetic resources (Funded by BARC-SPGR- NATP: Phase I).

\section{References}

Dellaporta SL, Wood J and Hicks JB (1983) A plant DNA mini preparation: version II. Plant Mol. Biol. Rep. 1: 19-21. DOI: $10.1007 / \mathrm{BF} 02712670$

Doyle JJ and Doyle JL (1990) Isolation of plant DNA from fresh tissue. Focus. 12: 13-15.

Haque S, Ashraf N, Awal A, Sarker RH, Begum S and Khan H (2004) Method for quality DNA isolation from different parts of Jute plant: Corchorus capsularis L. and Corchorus olitorius L. Plant Tissue Cult. 14: 143-148.

Haque S, Begum S, Sarker RH and Khan H (2007) Determining genetic diversity of some Jute varieties and accessions using RAPD markers. Plant Tissue Cult. Biotechnol. 17: 183-191.

Ogunkanmi LA, Okunowo W, Oyelakin OO, Oboh BO, Adesina OO, Adekoya KO and Ogundipe OT (2004) Assessment 
of genetic relationship between two species of Jute plants using phenotypic and RAPD markers. Int. J. Bot. 6: 107111.

Porebski S, Bailey LG and Baum BR (1997) Modification of a CTAB DNA extraction protocol for plants containing high polysaccharide and polyphenol components. Plant Mol. Biol. Rep. 15: 8-15. DOI: 10.1007/BF02772108
Rahman SN, Islam MS, Alam MS and Nasiruddin KM (2006) Genetic polymorphism in rice (Oryza sativa L.) thorough RAPD analysis. Indian J. Biotechnol. 6: 224-229.

Saha CK (2006) Morphological, molecular characterization and agrobacterium mediated genetic transformation in Jute (Corchorus spp.). PhD thesis, Department of Genetics and Plant Breeding, Bangladesh Agricultural University, Mymensingh 